\title{
pH-responsive protein microcapsules fabricated via glutaraldehyde mediated covalent layer-by-layer assembly
}

\author{
Weijun Tong • Changyou Gao • Helmuth Möhwald
}

Received: 21 March 2008 /Revised: 28 April 2008 / Accepted: 6 May 2008 /Published online: 1 June 2008

(C) The Author(s) 2008

\begin{abstract}
Bovine serum albumin (BSA) hollow microcapsules were fabricated through glutaraldehyde (GA) mediated covalent layer-by-layer assembly. The GA crosslinking of the adsorbed BSA on the colloidal particles enabled their surfaces to be covered by reactive aldehyde groups, which reacted with BSA molecules to result in another covalently linked layer. Repeating of this cycle could then yield particles coated with BSA multilayers. Hollow microcapsules well dispersed in water were obtained after core removal. The good integrity and morphology of the BSA capsules were confirmed and characterized by confocal laser scanning microscopy, scanning electron microscopy and scanning force microscopy. The obtained BSA microcapsules possess reversible $\mathrm{pH}$ response, i.e., the capsules are permeable to macromolecules below $\mathrm{pH} 4$ or above $\mathrm{pH} 10$, while impermeable in between. The mechanisms of permeability transition were discussed. Using this property, dextran, with a molecular weight of $\sim 155 \mathrm{kDa}$, was successfully loaded.
\end{abstract}

Keywords Bovine serum albumin · Glutaraldehyde . Covalent layer-by-layer $\cdot \mathrm{pH}$-responsive $\cdot$ Microcapsules

\footnotetext{
W. Tong $\cdot$ C. Gao $(\bowtie)$

Key Laboratory of Macromolecular Synthesis and Functionalization, Ministry of Education, Department of Polymer Science and Engineering, Zhejiang University, Hangzhou 310027, China

e-mail: cygao@mail.hz.zj.cn

W. Tong $\cdot$ H. Möhwald

Max-Planck-Institute of Colloids and Interfaces,

14424 Potsdam, Germany
}

\section{Introduction}

Protein nano-/microspheres and capsules for controlled and/ or sustained release have attracted considerable attention for pharmaceutical and other applications [1-9]. As natural biomacromolecules, proteins are generally considered to be biocompatible and biodegradable. Most previous studies focused on different kinds of albumins [1-3], milk protein caseins [4-7], as well as whey proteins $[8,9]$, because they are abundant in nature and inexpensive. The most frequently employed procedure for fabricating the protein microspheres is as follows. An aqueous solution of proteins which may contain drugs is dispersed in an organic phase to form a reverse emulsion. Then cross-linking of the droplets is conducted to stabilize the structure, resulting in the microspheres [3]. Although the droplet size of the emulsion, and thus the resulting microsphere size, is determined by the nature of the dispersion, the spheres with smaller size and narrower size distribution are difficult to obtain. By other methods such as desolvation of the protein solution followed by cross-linking [10] or electrospray drying [11], protein nanoparticles can be fabricated.

Compared with spheres, hollow protein capsules have larger capacity to load desired substances. Several approaches have been developed to fabricate hollow protein capsules. For example, bovine serum albumin (BSA) capsules with disulfide cross-linked shells of $\sim 50 \mathrm{~nm}$ and cores containing air or non-aqueous liquid were prepared using ultrasonic emulsification $[12,13]$. In another case, the hollow protein capsules with a size of tens of microns were fabricated through protein adsorption on the pendent organic droplets followed by evaporation of the organic solvent [14]. However, the above-mentioned methods are not applicable for fabricating capsules with defined size, wall thickness and compositions. More recently, a new 
method combining colloidal templating and layer-by-layer (LbL) assembly [15, 16], followed by core removal, produces hollow microcapsules with precisely controlled structures and properties [17-19]. Of special interest is that it is possible to tune the stimuli-responsive properties of the capsule by incorporation of functional molecules into their wall or interior, thus the loading and subsequent release of diverse substances into/from the microcapsules can be controlled in a desired manner. By this method, the hollow microcapsules with proteins or enzymes as one of the wall compositions also have been obtained [20-23]. But in most of the cases, the capsule walls are based on the electrostatic interaction.

Glutaraldehyde (GA) is most widely used as a crosslinking reagent for preparation of protein spheres and capsules because its aldehyde groups can easily react with amine groups at mild conditions. In our previous studies, GA was used to cross-link polyelectrolyte microcapsules to manipulate their properties $[24,25]$. More recently, we developed a GAmediated covalent layer-by-layer assembly method to fabricate single component polyelectrolyte microcapsules [26, 27]. Hemoglobin capsules and nanotubes with retained activity were fabricated in a similar way [28, 29]. The single component polyelectrolyte microcapsules are robust and their properties can be controlled by the molecular weight of used polyelectrolyte [26, 27]. However, due to the high cross-linking density the capsules lost their stimuli-response.

BSA has a high content of charged residues of amino acids, such as aspartic and glutamic acids, lysine, and arginine [30, 31]. GA only cross-links the amine group of lysine [32], while the other charged residues of amino acids still exist. Consequently, $\mathrm{pH}$ response of the resultant products can be expected. Moreover, previous studies have shown that the GA-cross-linked albumin microspheres are relatively non-immunogenic and biodegradable in muscle without adverse tissue reactions [2]. Therefore, the GA cross-linked BSA spheres/capsules are promising for pharmaceutical applications. Herein, we describe the preparation of BSA microcapsules fabricated in a covalent layer-by-layer assembly manner through GA cross-linking. In this approach, BSA is first assembled on the surfaces of the colloidal templates. Then the coated particles are suspended in GA solution to cross-link the adsorbed BSA layer and activate the surface for the next covalent assembly of BSA. This procedure is repeated several times until the desired layer number is reached. Hollow capsules are obtained by removal of the cores. The microstructure of the obtained BSA microcapsules is investigated by confocal laser scanning microscopy (CLSM), scanning electron microscopy (SEM) and scanning force microscopy (SFM). The capsules show reversible $\mathrm{pH}$-controlled permeability, which can be used to encapsulate macromolecules. The possible mechanisms of $\mathrm{pH}$ response are discussed.

\section{Experimental section}

\section{Materials}

BSA, tetramethylrhodamine isothiocyanate labeled dextran (TRITC-dextran, $\mathrm{Mw} \sim 155 \mathrm{kDa}$ ), rhodamine $6 \mathrm{G}$ (Rd6G), manganese sulfate hydrate $\left(\mathrm{MnSO}_{4} \cdot \mathrm{H}_{2} \mathrm{O}\right)$, disodium ethylenediaminetetraacetate dihydrate (EDTA), ammoniumhydrogencarbonate $\left(\mathrm{NH}_{4} \mathrm{HCO}_{3}\right)$ and glutaraldehyde (GA, 50 wt.\% solution in water) were all obtained from Sigma-Aldrich. All the chemicals were used as received. The water used in all the experiments was prepared in a three-stage Millipore Milli-Q Plus 185 purification system and had a resistivity higher than 18.2 $\mathrm{M} \Omega$. Spherical $\mathrm{MnCO}_{3}$ microparticles with an average diameter of $7.4 \pm 0.4 \mu \mathrm{m}$ were synthesized according to literature by mixing $\mathrm{MnSO}_{4}$ and $\mathrm{NH}_{4} \mathrm{HCO}_{3}$ solutions $[33,34]$.

\section{Methods}

\section{Multilayer build-up onto planar substrate}

Silicon wafers were treated with $\mathrm{H}_{2} \mathrm{O}_{2} / \mathrm{H}_{2} \mathrm{SO}_{4}(30 / 70 v / v)$ solution for $1 \mathrm{~h}$ and thoroughly rinsed with water. The pre-treated substrates were sequentially immersed into BSA (4 mg/ml, in $0.5 \mathrm{M} \mathrm{NaCl}, \mathrm{pH}=4.7)$ and $\mathrm{GA}$ solutions $(2 \%)$ for $30 \mathrm{~min}$, with three water rinses at each interval. After each BSA assembly, the surface water of the multilayer was blown away by flowing nitrogen and the thickness of the film was measured immediately by ellipsometry.

\section{Fabrication of hollow protein microcapsules}

BSA was adsorbed onto the $\mathrm{MnCO}_{3}$ microparticles under the same conditions employed for its multilayer construction on planar substrate. After BSA adsorption, the excess proteins were removed by centrifugation at $300 \times g$ for $5 \mathrm{~min}$, and the coated particles were washed three times with water. Then the particles were dispersed in the GA solution for $30 \mathrm{~min}$, followed by three washings. The crosslinked and surface activated particles were dispersed in the protein solution again. This procedure was repeated until ten BSA layers were assembled. The coated particles were further cross-linked with 2\% GA solution for $12 \mathrm{~h}$ to stabilize the structure. After washing with water five times, the coated particles were incubated in $0.1 \mathrm{M} \mathrm{HCl}$ solution for $30 \mathrm{~min}$ under continuous shaking to remove the cores. The resultant capsules were washed three times with $0.01 \mathrm{M}$ EDTA solution to rinse off the $\mathrm{Mn}^{2+}$. Finally, the capsules were washed three times with water and dispersed in water. 


\section{Ellipsometry}

Ellipsometry was performed using an optical null ellipsometer (Multiskop Ellipsometer, Optrel $\mathrm{GmbH}$ ) with a $\mathrm{He}-$ $\mathrm{Ne}$ laser at $632.8 \mathrm{~nm}$ at an angle of $70^{\circ}$. Silicon wafers were used as the substrates for the multilayer formation and were cleaned as described above. A refractive index value of 1.32 for BSA multilayer was measured from ten-layer film and used for all the calculations. Each point was averaged from ten individual measurements.

\section{Confocal laser scanning microscopy (CLSM)}

Confocal images were taken with a Leica confocal scanning system mounted to a Leica Aristoplan and equipped with a $100 \times$ oil immersion objective with a numerical aperture (NA) of 1.4. For visualization, Rd6G was used to stain the BSA capsules. To investigate the permeability, a drop of the capsule suspension was mixed with the fluorescent probes solution with same $\mathrm{pH}$ and observed after $30 \mathrm{~min}$.

\section{Scanning electron microscopy (SEM)}

Samples were prepared by applying a drop of the capsule suspension onto glass slides. After dried overnight, the samples were sputtered with gold and measured by a Gemini Leo 1550 instrument at an operation voltage of $3 \mathrm{keV}$.

\section{Scanning force microscopy (SFM)}

A drop of the sample suspension was applied onto freshly cleaved mica and dried overnight at room temperature. Images were obtained by a Digital Instruments nanoscope IIIa Multimode SFM (Digital Instruments Inc., Santa Barbara, $\mathrm{CA}$ ) in air at room temperature using the tapping mode.

\section{$\zeta$-potential measurement}

The $\zeta$-potentials of BSA microcapsules were measured at different $\mathrm{pHs}$ by a Zetasizer Nanoinstrument Nano Z equipment. The $\mathrm{pH}$ was adjusted by $0.1 \mathrm{M} \mathrm{NaOH}$ or $\mathrm{HCl}$. Each value was averaged from three parallel measurements.

\section{Results and discussion}

Protein multilayer built up on planar substrate

The reaction of GA with diverse proteins has been extensively studied and the reaction is $\mathrm{pH}$-dependent [35]. Jansen et al. [36] showed that the optimum $\mathrm{pH}$ for GA insolubilization varies from proteins to proteins. Specially, the $\mathrm{pH}$ for the most rapid insolubilization of BSA was found to be nearly the same as its isoelectricpoint (pI; pH 4.7). The existence of an optimum $\mathrm{pH}$ suggests the important role of the protein charge on the intermolecular cross-linking which is required for the formation of insoluble protein layer. The charge on the protein may regulate cross-linking, which is maximal when the repulsive charges are minimal. One more recent study also confirmed that shielding the electrostatic repulsion is necessary for the successful LbL assembly of like charged polyelectrolyte [37]. So here the $\mathrm{pH} 4.7$ (the $\mathrm{pI}$ of BSA) and relatively high ionic strength $(0.5 \mathrm{M} \mathrm{NaCl})$ were used for the construction of BSA multilayers. First, the BSA multilayers were assembled on silicon wafer for the sake of monitoring the film growth by ellipsometry. Figure 1 shows that the film thickness increases steadily in a linear way with the increase of layer number. The average increment of one BSA layer is about $3 \mathrm{~nm}$. The crystal structure of albumin reveals a heart-shape molecule that can be approximated to an equilateral triangle with sides of $\sim 8 \mathrm{~nm}$ and a depth of $\sim 3 \mathrm{~nm}$ [31]. Therefore, here each absorbed BSA layer is more likely a monolayer. These results confirm that mediated via GA, the BSA multilayers can be successfully built up on a planar surface and its thickness increment can be controlled at the nanometer scale.

Hollow protein microcapsules

In order to obtain capsules with good integrity, the freestanding multilayers of the microcapsules should be strong enough to resist the osmotic pressure during the core removal process $[38,39]$. Therefore, the ten-layer BSA

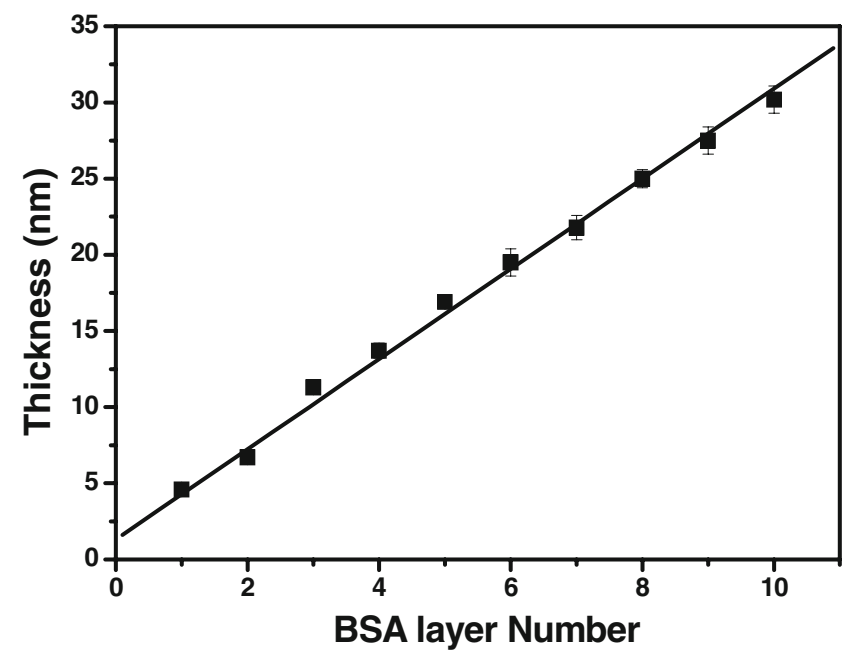

Fig. 1 The thickness of the BSA multilayers formed on the silicon wafer as a function of layer number, determined by ellipsometry. The solid line is a linear fit of the data 
Fig. 2 CLSM image (a) and SEM image (b) of the ten-layer BSA hollow microcapsules. The inset of $\mathbf{b}$ is a magnified capsule; the scale bar $=2 \mu \mathrm{m}$
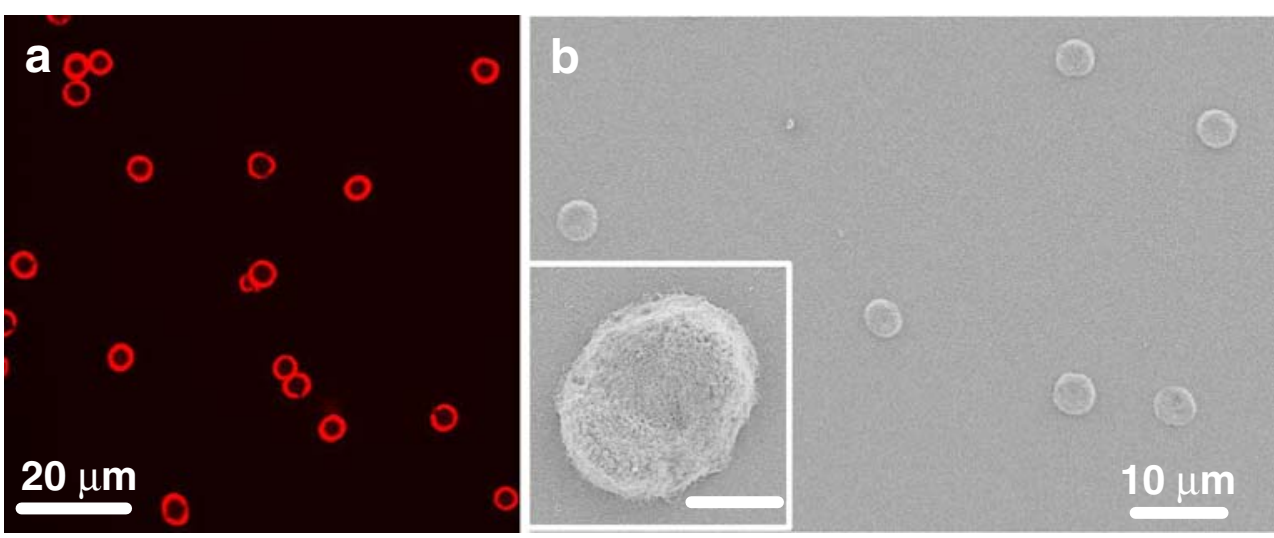

coated particles were further cross-linked with GA for $24 \mathrm{~h}$ to stabilize the structure. The post treatment with longer reaction time is necessary because the reaction of GA with lysine residues is progressive with time, probably depending on the accessibility of the amino groups [40, 41]. Then the $\mathrm{MnCO}_{3}$ templates were removed and the BSA capsules were washed with EDTA solution and water. Visualized under CLSM (Fig. 2a), the obtained microcapsules are well dispersed in water and resemble the shape of their templates as those fabricated by the traditional electrostatic assembly. However, their size shrinks from $7.4 \pm 0.4 \mu \mathrm{m}$ (core size) to $5.1 \pm 0.3 \mu \mathrm{m}$. Size shrinkage after core removal was also observed for polypeptide microcapsules and nanoporous protein spheres [42, 43]. Molecular relaxation should contribute partially to this phenomenon. Recent studies show that the balance between hydrophobicity and hydrophilicity contributes to surface energy of the capsules, which may cause shrinkage if hydrophobicity dominates, or expansion if the lateral electrostatic repulsion dominates [44].

After evaporation of the water, the hollow capsules collapse (Fig. 2b) to a pancake topology without typical folds and creases often observed in traditional multilayer microcapsules [18]. The SFM images provide more clear visualization (Fig. 3a). Here we make two assumptions for estimating the wall thickness after shrinkage: the thickness of the BSA multilayers assembled on the $\mathrm{MnCO}_{3}$ particles
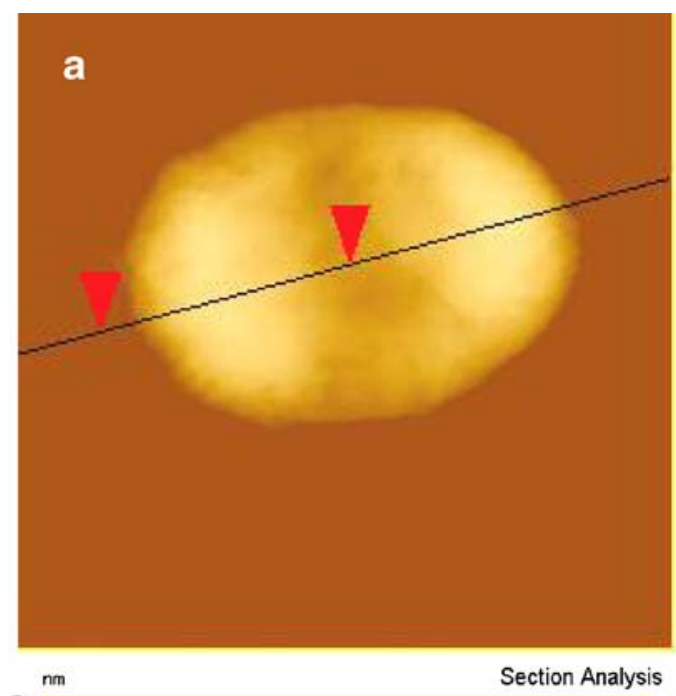

․- -

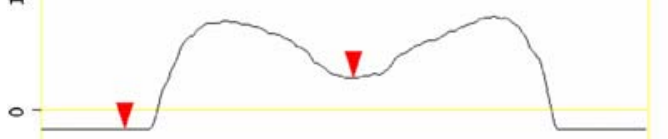

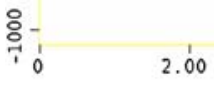

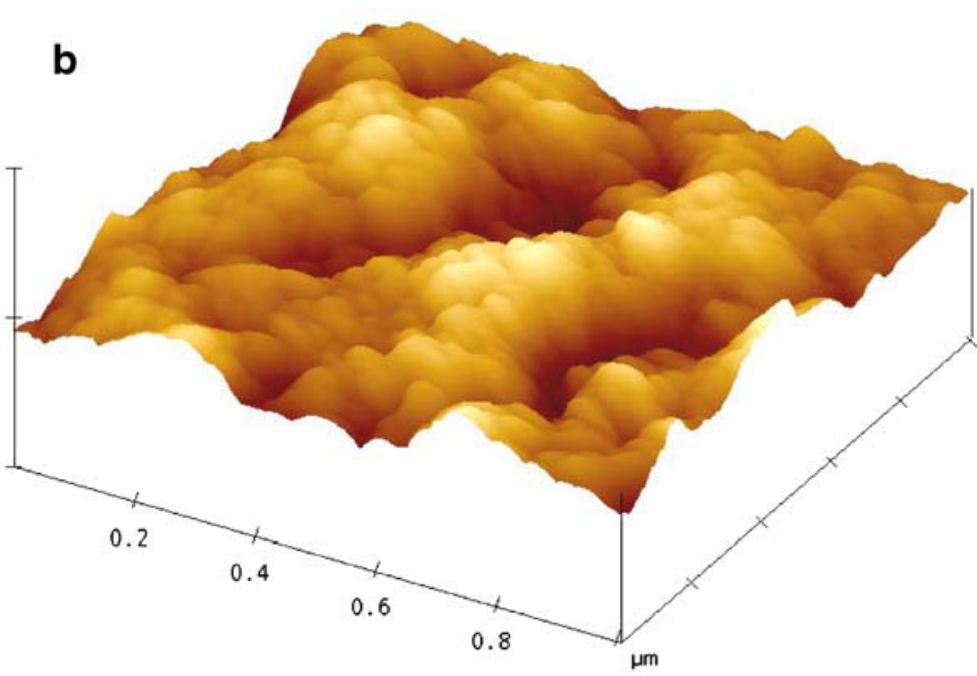

Image statistics

\begin{tabular}{ll|} 
Img. Z range & $80.419 \mathrm{~nm}$ \\
Img. Rms (Rq) & $11.346 \mathrm{~nm}$ \\
Img. Ra & $8.843 \mathrm{~nm}$ \\
Img. Rmax & $80.419 \mathrm{~nm}$ \\
Img. Srf. area & $1.083 \mathrm{\mu m}^{2}$
\end{tabular}

Fig. 3 SFM image (a) of the ten-layer BSA hollow microcapsules. b is a higher magnification of a flat part of the capsule shown in (a) 


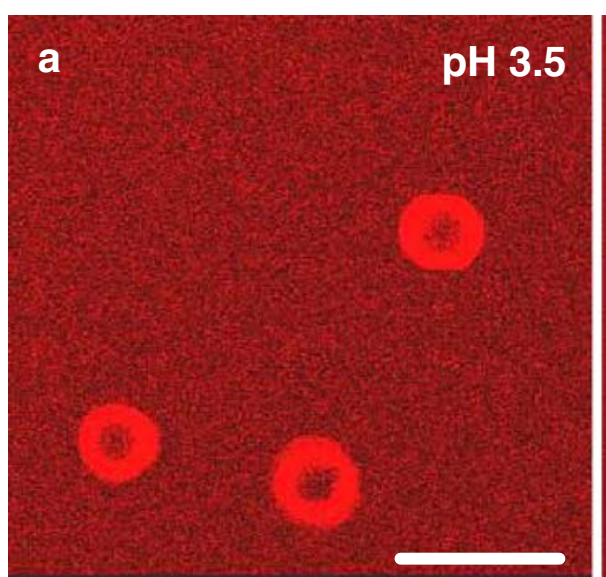

Fig. 4 CLSM images of the ten-layer BSA microcapsules after mixed with TRITC-dextran $(\mathrm{Mw} \sim 155 \mathrm{kDa})$ for $30 \mathrm{~min}$ at different $\mathrm{pHs}$ : a $\mathrm{pH}$ $3.5, \mathbf{b} \mathrm{pH} 6.5$ and $\mathbf{c} \mathrm{pH}$ 10.3. The capsules are impermeable to

before core removal is equal to that on the planar silicon wafer, and there is no material loss during the capsule shrinkage after core removal, thus the volume of the wall should keep constant in a dry state. Therefore, the thickness of the capsule walls should increase after capsule shrinkage, and the double wall thickness is estimated as $\sim 126 \mathrm{~nm}$. This value is far larger than that of the traditional polyelectrolyte multilayers with the same layer number $(\sim 40 \mathrm{~nm})$ [18]. However, it is still smaller than the apparent double wall thickness $(\sim 300 \mathrm{~nm})$ measured from the minimum height of the capsules in the SFM images, indicating that more materials are adsorbed onto the rough $\mathrm{MnCO}_{3}$ particles and the capsules may not be completely collapsed and flattened. These facts can explain the morphology difference between the BSA microcapsules and the polyelectrolyte microcapsules observed from the SEM and AFM images. The capsule surface shows a rough morphology with a ridgelike structure (root-mean-squared roughness (RMS) on $1 \mu \mathrm{m} \times 1 \mu \mathrm{m}$ was $11.3 \mathrm{~nm}$; Fig. 3b). Grains and domains ranging from tens to hundreds of nanometers also can be macromolecules in the $\mathrm{pH}$ range of $4 \sim 10$, while are permeable below $\mathrm{pH} 4$ or above 10. Scale bar $=10 \mu \mathrm{m}$

seen. We suppose that the shrinkage of the capsule should greatly influence the surface morphology to induce the wrinkled and rough structure.

pH-controlled permeability of the protein microcapsules

The permeability of the hollow BSA capsules is particularly interesting due to its close relationship with diverse applications. Thus the permeation of low-molecular-weight dyes as well as macromolecules was investigated by CLSM after incubation for $30 \mathrm{~min}$. It was found that the BSA microcapsules are permeable for low-molecular-weight dyes, such as Rd6G (data not shown). However, the situation is different for TRITC-dextran with a molecular weight of $155 \mathrm{kDa}$. Representative CLSM images obtained at different pHs are shown in Fig. 4. At acidic and alkaline conditions, e.g., $\mathrm{pH} 3.5$ and 10.3, respectively (Fig. 4a,c), the capsules have the same fluorescence intensity inside as the bulk solution, implying that the dextran can penetrate inside. By sharp contrast, at neutral $\mathrm{pH}(\mathrm{pH}$ 6.5), the
Fig. 5 CLSM images of the BSA microcapsules loaded with TRITC-dextran (Mw $155 \mathrm{kDa})$ through the $\mathrm{pH}$-controlled permeability switching protocol. The capsules were incubated with TRITC-dextran solution at (a) $\mathrm{pH} \mathrm{3.5,} \mathrm{(b)} \mathrm{pH} 10.3$ for 30 min and washed after the $\mathrm{pH}$ was adjusted to 6.5. Scale bar= $10 \mu \mathrm{m}$
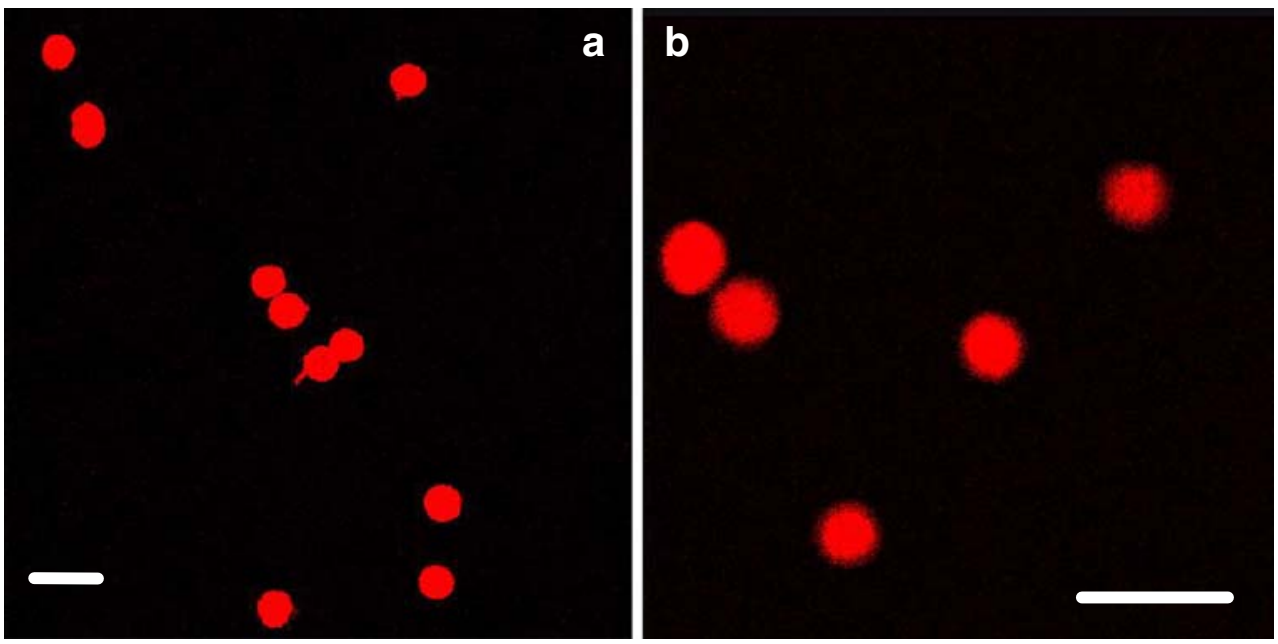
interiors of the capsules remain dark at least for $30 \mathrm{~min}$ (Fig. 4b), implying that the dextran can not penetrate inside. This image reveals also that most of the capsules preserve their good integrity after core removal. We checked the $\mathrm{pH}$ range of $1 \sim 12$. The transition points of permeability for macromolecules were found around $\mathrm{pH} 4$ and $\mathrm{pH} 10$. In other words, the $\mathrm{pH}$ values for the TRITC-dextran to permeate inside are $<4$ and $>10$. It is worth mentioning that the size of the capsule remained constant $(5.1 \pm 0.3 \mu \mathrm{m})$ at $\mathrm{pH}$ below 10 , while increased to $6.1 \pm 0.3 \mu \mathrm{m}$ at $\mathrm{pH}$ above 10 . Both of the $\mathrm{pH}$-responsive permeability and swelling are reversible.

The pH-responsive properties have been reported for different multilayer capsules $[25,45-50]$. It has been suggested that the change of the polyelectrolyte charges upon $\mathrm{pH}$ variation might induce reorganization of the wall structure or loosen the polyelectrolyte networks, enabling the macromolecules to penetrate $[25,45,50]$. The lateral electrostatic repulsion between the same net charges resulting from the $\mathrm{pH}$ change is considered as the main driving force to induce a swelling of the whole structure [46-48]. Moreover, the attraction of counterions by the net charge may increase the local osmotic pressure and contribute to the swelling effect [48]. Generally, the swelling of the capsules is accompanied by the increase of permeability $[46,51]$. This mechanism should be applicable to the swelling and the enhanced permeability of the BSA capsules at $\mathrm{pHs}$ above 10. Albumins are characterized by a high content of charged amino acids, such as aspartic and glutamic acids, lysine, and arginine [30, 31]. GA crosslinking only modifies the amine group of lysine [32], so the carboxyls still exist and are almost fully charged at $\mathrm{pH}$ above 10 to gain a net negative charge in the capsule walls. To confirm this point, the $\zeta$-potentials of the BSA hollow capsules were investigated at different $\mathrm{pHs}$. The results showed that at $\mathrm{pH} \mathrm{10,} \mathrm{the} \mathrm{capsules} \mathrm{are} \mathrm{more} \mathrm{negatively}$ charged $(-23.8 \pm 3.5 \mathrm{mV})$ than that at $\mathrm{pH} 6.5(-13.3 \pm$ $1.9 \mathrm{mV})$. The result implies also although the capsules possess net negative charge at neutral $\mathrm{pH}$, the value is not high enough to cause the swelling of the capsules.

Albumin was reported to undergo a major reversible conformation change with changes of $\mathrm{pH}[30,31]$. In a previous study [23], a permeability increase of human serum albumin (HSA)/lipids microcapsules was also observed at $\mathrm{pH}$ below 4.8. The expanded conformation of HSA is believed to disorder the structure of lipid bilayers, thus enhancing the permeation of macromolecules. To investigate whether the conformation change near $\mathrm{pH} 4$ induces the permeability change or not, we deposited the BSA multilayers on the inner surface of a quartz cell and filled the cell with water with pHs of 3.5, 4, and 4.5 then measured the circular dichroism (CD) spectra. No obvious difference was found between these spectra (data not shown). We measured the $\zeta$-potential of the BSA microcapsules at $\mathrm{pH} 4$ also, and found a value of $-1.4 \pm 1.2 \mathrm{mV}$. Therefore, at least from the viewpoint of charge interaction, we believe that the microstructure of the microcapsules should have been similarly altered as that in the basic solution, since the absolute variable values at lower and higher $\mathrm{pH}$ are almost same $(\sim 10 \mathrm{mV})$.

The ability of reversible permeability switching provides a facile and effective way to control the loading and release of various macromolecules. For example, the capsules were incubated in TRITC-dextran $(\mathrm{Mw} \sim 155 \mathrm{kDa})$ solution at $\mathrm{pH}$ 3.5 or 10.5 for $30 \mathrm{~min}$, and then the $\mathrm{pH}$ value was adjusted to 6.5. After removal of the bulk solution by centrifugation and washing, TRITC-dextran was successfully loaded into the microcapsules as verified by the strong fluorescence from the capsule interiors (Fig. 5). The encapsulated macromolecules did not leak out at least for 2 weeks (data not shown).

\section{Conclusion}

We describe here the fabrication of hollow BSA microcapsules through a GA-mediated covalent LbL assembly method and subsequent core removal. The linear growth of the BSA multilayers as a function of layer number was monitored by ellipsometry, illustrating that the increment of the thicknesses can be controlled in a nanometer scale. These BSA capsules exhibit reversible pH-responsive permeability. They are permeable for macromolecules at pH below 4 or above 10, while are impermeable in between. The permeability transition at $\mathrm{pH} 10$ is attributed to the swelling of the capsules as a result of charge repulsion. Using this feature, macromolecules can be loaded and sealed for at least for 2 weeks. This method can be extended to other proteins and enzymes also, which are not only biocompatible but also bioactive. The protein microcapsules with $\mathrm{pH}$-tunable permeability are relevant to many applications, especially those related with drug release.

Acknowledgments We thank Prof. J. C. Shen for his continuous support and stimulating discussions. A. Heilig and Dr. G. Zhang are greatly acknowledged for their assistance in SFM and SEM measurements, respectively. W.J. Tong and C.Y. Gao thank the Max-Planck Society for a visiting scientist grant. This study is financially supported by China Postdoctoral Science Foundation (Nos. 20070421171), the Natural Science Foundation of China (Nos. 20434030, 20774084) and the National Science Fund for Distinguished Young Scholars of China (No. 50425311).

Open Access This article is distributed under the terms of the Creative Commons Attribution Noncommercial License which permits any noncommercial use, distribution, and reproduction in any medium, provided the original author(s) and source are credited. 


\section{References}

1. Arshady R (1990) J Control Release 14:111

2. Lee TK, Sokoloski TD, Royer GP (1981) Science 213:233

3. Longo WE, Iwata H, Lindheimer TA, Goldberg EP (1982) J Pharm Sci.-US 71:1323

4. Chen Y, Willmott N, Anderson J, Florence AT (1987) J Pharm Pharmacol 39:978

5. Knepp WA, Jayakrishnan A, Quigg JM, Sitren HS, Bagnall JJ, Goldberg EP (1993) J Pharm Pharmacol 45:887

6. Latha MS, Rathinam K, Mohanan PV, Jayakrishnan A (1995) J Control Release 34:1

7. Willmott N, Magee GA, Cummings J, Halbert GW, Smyth JF (1992) J Pharm Pharmacol 44:472

8. Heelan BA, Corrigan OI (1998) J Microencapsul 15:93

9. Lee SJ, Rosenberg M (1999) J Control Release 61:123

10. Weber C, Coester C, Kreuter J, Langer K (2000) Int J Pharm 194:91

11. Gomez A, Bingham D, de Juan L, Tang K (1998) J Aerosol Sci 29:561

12. Suslick KS, Grinstaff MW (1990) J Am Chem Soc 112:7807

13. Grinstaff MW, Suslick KS (1991) Proc Nat Acad Sci U.S.A. 88:7708

14. Lu G, An ZH, Tao C, Li JB (2004) Langmuir 20:8401

15. Decher G (1997) Science 277:1232

16. Decher G, Hong JD, Schmitt J (1992) Thin Solid Films 210:831

17. Caruso F, Caruso RA, Möhwald H (1998) Science 282:1111

18. Donath E, Sukhorukov GB, Caruso F, Davis SA, Möhwald H (1998) Angew Chem Int Edit 37:2202

19. Peyratout CS, Dähne L (2004) Angew Chem Int Edit 43:3762

20. Tiourina OP, Sukhorukov GB (2002) Int J Pharm 242:155

21. Balabushevich NG, Tiourina OP, Volodkin DV, Larionova NI, Sukhorukov GB (2003) Biomacromolecules 4:1191

22. An ZH, Tao C, Lu G, Möhwald H, Zheng SP, Cui Y, Li JB (2005) Chem Mater 17:2514

23. An ZH, Möhwald H, Li JB (2006) Biomacromolecules 7:580

24. Tong WJ, Gao CY, Möhwald H (2005) Chem Mater 17:4610

25. Tong WJ, Gao CY, Möhwald H (2006) Macromolecules 39:335

26. Tong WJ, Gao CY, Möhwald H (2006) Macromol Rapid Comm 27:2078
27. Tong WJ, Gao CY, Möhwald H (2008) Polym Advan Technol DOI 10.1002/pat.1040 (in press)

28. Duan L, He Q, Yan XH, Cui Y, Wang KW, Li JB (2007) Biochem Bioph Res Co 354:357

29. Hou SF, Wang JH, Martin CR (2005) Nano Letters 5:231

30. Peters $T$ (1985) Adv Protein Chem 37:161

31. Carter DC, Ho JX (1994) Adv Protein Chem 45:153

32. Rubino OP, Kowalsky R, Swarbrick J (1993) Pharm Res 10:1059

33. Antipov AA, Shchukin D, Fedutik Y, Petrov AI, Sukhorukov GB, Möhwald H (2003) Colloid Surface A 224:175

34. Tong WJ, Gao CY (2007) Colloid Surface A 295:233

35. Habeeb AFS, Hiramoto R (1968) Arch Biochem Biophys 126:16

36. Jansen EF, Tomimats Y, Olson AC (1971) Arch Biochem Biophys 144:394

37. Johnston APR, Read ES, Caruso F (2005) Nano Letters 5:953

38. Gao CY, Moya S, Donath E, Möhwald H (2002) Macromol Chem Phys 203:953

39. Gao CY, Moya S, Lichtenfeld H, Casoli A, Fiedler H, Donath E, Möhwald H (2001) Macromol Mater Eng 286:355

40. Bullock GR (1984) J Microsc-Oxford 133:1

41. Ottesen M, Svensson B, Trav CR (1971) Lab Carlsberg 38:171

42. Yu AM, Wang YJ, Barlow E, Caruso F (2005) Adv Mater 17:1737

43. Wang YJ, Caruso F (2006) Adv Mater 18:795

44. Köhler K, Möhwald H, Sukhorukov GB (2006) J Phys Chem B 110:24002

45. Antipov AA, Sukhorukov GB, Leporatti S, Radtchenko IL, Donath E, Möhwald H (2002) Colloid Surface A 198:535

46. Déjugnat C, Haložan D, Sukhorukov GB (2005) Macromol Rapid Comm 26:961

47. Déjugnat C, Sukhorukov GB (2004) Langmuir 20:7265

48. Mauser T, Déjugnat C, Sukhorukov GB (2004) Macromol Rapid Comm 25:1781

49. Shutava T, Prouty M, Kommireddy D, Lvov Y (2005) Macromolecules 38:2850

50. Sukhorukov GB, Antipov AA, Voigt A, Donath E, Möhwald H (2001) Macromol Rapid Comm 22:44

51. Gao CY, Möhwald H, Shen JC (2004) Chemphyschem 5:116 